\title{
Patient-Reported Outcomes in Subjects With A143T and R118C GLA Gene Variants
}

Journal of Inborn Errors of Metabolism \& Screening 2021, Volume 9: e20210016 DOI: https://doi.org/10.1590/2326-4594JIEMS-2021-0016

\author{
Nilton Salles Rosa Neto' (1), Judith Campos de Barros Bento' \\ and Rosa Maria Rodrigues Pereira'
}

\begin{abstract}
Background: Fabry disease (FD) is caused by pathogenic variants in the GLA gene. A143T and R118C variants are considered not disease causing. Patient-reported outcomes provide information concerning the effects of their disease but should be carefully analyzed in rare diseases.
\end{abstract}

Objectives: To evaluate pain, depression, sleep disturbances, disability and quality of life in A143T or R118C Brazilian subjects and compare to data published for classic FD patients.

Methods: Nineteen subjects - 8:11 male:female - were evaluated and answered the questionnaires: Brief Pain Inventory (BPI), Hamilton Depression Rating Scale, Pittsburgh Sleep Quality Index, Health Assessment Questionnaire Disability Index (HAQ-DI), Short-Form Health Survey 36 (SF-36). Lyso-Gb3 and residual enzyme activity were obtained.

Results: Alpha-galactosidase A activity was low in males. Lyso-Gb3 levels were normal in all subjects. Comparing A143T/R118C subjects and FD patients, BPI severity, BPI interference, HAQ-DI values were not different $(p>0.05)$ whereas raw scores for physical functioning $(p=0.01)$ and general health perception $(p<0.01)$ favored A143T/R118C. Depression and sleep disturbances were similar between groups.

Conclusions: A143T/R188C subjects had normal lyso-Gb3 levels. Depression, sleep disturbances and disability were frequent and under-recognized. However, findings depicted in this study are nonspecific and should not be considered as ground for diagnosing Fabry disease.

Keywords: Fabry disease, Patient-reported outcomes, Depression, Sleep disturbances, Disability, Quality of life.

\section{Background}

Fabry disease (FD) is caused by pathogenic variants on the GLA gene located on the $\mathrm{X}$ chromosome which affect alphagalactosidase A function.[1,2] FD is a multisystemic disease that may present with variable signs and symptoms that may ultimately culminate in heart and kidney compromise, stroke, chronic pain, and impaired quality of life.[3-5] The symptoms are progressively debilitating, reduce the ability of patients to attend work or school and severely affect quality of life.[1,3] Of note, phenotypic variability is noticeable in patients sharing the same pathogenic variant, even within members of the same family.[6]

Screening for FD in the neonatal period or in the setting of chronic kidney disease, cardiomyopathy or cerebrovascular events of unknown etiology may disclose patients harboring GLA gene variants that are not necessarily related to the underlying problem and be a motivation for misdiagnosis.[7-9]

Criteria to determine pathogenicity of a variant include a) identification of reduced alpha-galactosidase A enzymatic function (being FD X-linked, it is most appropriately assessed on male probands); b) presence of typical signs and symptoms associated with the disease (in this case cornea verticillata is usually a more sensitive finding); and c) demonstration of substrate accumulation on a target organ (most frequently from kidney biopsies and, sometimes, myocardium biopsies).[10] Depending on disease presentation, such information may not always be available, or obtained, and surrogate biomarkers may be required to support diagnosis.[11] Clinical and instrumental evaluation of patients is important for a more accurate diagnostic assessment.[12]LysoGb3 (globotriaosylsphingosine) has been considered a useful

\footnotetext{
${ }^{1}$ Universidade de São Paulo, Faculdade de Medicina, São Paulo, SP, Brazil.
}

Received march 11, 2021, and in revised form april 16, 2021. Accepted for publication april 19, 2021.

\section{Corresponding Author:}

Nilton Rosa Neto, Email: nsalles@yahoo.com 
biomarker for most patients since its levels correlate with the severity and progression of the disease in classic patients and may be modified by enzyme replacement therapy.[13]

Some GLA gene variants have little or no interference with enzyme activity, and therefore, absent, or mild FD attributes. Some variants may have minimal enzyme activity, but not enough to manifest evident disease. Under these situations, variants can be considered benign and not disease-causing while others, when precise information of pathogenicity or proven accumulation of sphingolipids in the altered tissue are not accessible, can be considered as genetic variants of unknown significance (GVUS).[10,14]

$\mathrm{R} 118 \mathrm{C}$ is a common benign variant that previously was thought to be disease-causing, but studies have demonstrated that it is not related with substrate accumulation. $[8,14]$ It is frequent among population with Spanish and Portuguese ancestry.[14,15] A143T is also most often regarded as not disease causing in most cases but some reports describe possible pathogenic link with cerebrovascular involvement.[16] The presence of the 5' untranslated region (UTR) of exon $110 \mathrm{C}>\mathrm{T}$ polymorphism may impact phenotype expression.[17] Judicious evaluation of residual enzyme activity in males, and lyso-Gb3 accumulation in both genders, may aid in the interpretation of pathogenicity.[13]

Patient-reported outcomes (PROs) have been assessed in FD and aspects such as depression and poor sleep quality are under-recognized and under-treated, aggravating the impact of the disease.[18-20] Importantly, it is not always possible to determine direct causality between substrate accumulation, inflammatory response, and symptom presentation in the event of psychological disorders in the setting of FD.[21] Several different factors may play a role in the development or worsening of these manifestations such as chronic pain, disability, exercise intolerance but also genetic predisposition, environmental issues, drug use and/or abuse, inadequate nutrition to name a few.[7,18,19,22-26] Prudent evaluation of the patients by a multidisciplinary team and phenotype-genotype correlation are important to avoid establishing a diagnosis in a patient with a benign variant who will likely not benefit from expensive FD targeted treatments.[26-28]

Of note, PROs have not been consistently evaluated in subjects with A143T and R118C GLA gene variants.

\section{Objectives}

To evaluate pain, depression, sleep disturbances, disability, and disease impact on quality of life in a small cohort of Brazilian subjects with A143T and R118C GLA gene variants and to compare to previously published results from classic FD patients from the same region (State of São Paulo, Brazil).

\section{Methods}

This is a sub-analysis from the protocol "Assessment of Parameters of Bone Metabolism in patients with Fabry Disease" that was undertaken at the Rheumatology Division, Faculdade de Medicina, Universidade de São Paulo, São Paulo, Brazil. This work was approved by Faculdade de Medicina da Universidade de São Paulo Ethics Review Board under number 1.464.841 on March $24^{\text {th }}, 2016$. All subjects read and signed informed consent. The procedures were followed in accordance with the ethical standards of the responsible committee on human experimentation and with the Helsinki Declaration of 1975, as revised in 1983.

Nineteen subjects with GLA gene variants A143T and R118C -8 male and 11 female - were referred for research purposes. The index cases from the different families were identified after screening protocols of patients in hemodialysis. They were interviewed by the same researcher (NSRN) and had clinical, laboratory and imaging data reviewed followed by the application of the questionnaires: Brief Pain Inventory (BPI) [29,30], Hamilton Depression Rating Scale (HAM-D) [31,32], Pittsburgh Sleep Quality Index (PSQI) [33,34], Health Assessment Questionnaire Disability Index (HAQ-DI) [35,36], Short-Form Health Survey 36 (SF-36). [37,38] All questionnaires were adapted and validated to Brazilian Portuguese. Details about each questionnaire are provided as Supplementary material.

The burden of the presenting disease, although not considered to be FD by the researcher, was assessed by the Mainz Symptom Severity Index (MSSI) [39] in the interest of comparison. MSSI categorizes FD patients in accordance with severity: low, moderate, or severe. Scores were established after interview with patients and chart review. Current and previous information on alpha-galactosidase A and lyso-Gb3 levels were available from the same laboratory (Centogene, Germany) and were collected to assess residual enzymatic activity in males and substrate accumulation in both genders.

Thirty-six genotype confirmed classic FD patients - 15 males and 21 females (variants: C142R, A156D, L180F, R227X, W262X, G271A, P293S, Y264SX) were assessed and used as comparators. The questionnaire-based results from the classic FD patients have already been published.[40]

\section{Statistical analysis}

Results are presented as mean and standard deviation for continuous variables and percentages for categorical variables. Correlation between continuous variables was measured by Pearson's correlation coefficient. We considered significant a $p$-value $<0.05$. 


\section{Results}

There were 4 subjects with variant A143T (1:3 male:female) and 15 subjects with variant R118C (7:8 male:female). The mean overall age (years) was $40.7 \pm 15.1$. Subjects with GLA gene variants A143T and R118C were stratified according to MSSI status as severe, moderate, or mild. MSSI scores disclosed 2 subjects that could be considered as having "moderate" disease and 17 subjects considered to have "mild" disease (Table 1). Interestingly, the two patients with "moderate" disease were being treated with enzyme replacement therapy (ERT) during the period of assessment at the discretion of their attending physicians. Alpha-galactosidase A residual enzyme activity level was low in all males and not done in females (Table 1). Lyso-Gb3 levels were in the normal range in all subjects (Table 1). Previously available lyso-Gb3 results for the two patients on ERT, preceding treatment initiation, were: Patient \#1 $1.8 \mathrm{ng} / \mathrm{ml}$ and Patient \#2 $0.9 \mathrm{ng} / \mathrm{ml}$ and $1.4 \mathrm{ng} / \mathrm{ml}$ at different occasions. All results were in the normal range (reference range $\leq 1.8 \mathrm{ng} / \mathrm{ml}$ ) and thus, excluding a possible confounding effect of ERT on the results. Noteworthy, the 2 patients on ERT had no histopathological proof of disease on affected targets.

\section{Pain}

In $\mathrm{A} 143 \mathrm{~T} / \mathrm{R} 118 \mathrm{C}$ subjects, mean \pm SD BPI severity result was $4.50 \pm 4.06$ for moderate and $3.05 \pm 3.35$ for mildly affected subjects. Mean \pm SD BPI interference result was $5.86 \pm 4.42$ for moderate and $2.20 \pm 3.18$ for mild subjects. BPI severity and interference values correlated with MSSI scores (severity: $r=0.40 ; \mathrm{p}=0.001$ / interference: $r=0.57 ; p<0.001$ ). Overall values of BPI severity and interference were not different from A143T/R118C subjects when compared to classic FD patients ( $3.21 \pm 2.97$ vs. $2.23 \pm 2.18, \mathrm{p}=0.17$ for severity and $2.59 \pm 2.98$ vs. $2.10 \pm 2.64, \mathrm{p}=0.54$ for interference).

Over-the-counter pain medication was used by 12 subjects (63.2\%). There was no report of opioid use. Only one subject (5.3\%) was treated with carbamazepine with migraine being the indication (female, R118C).

\section{Depression}

Depression was referred by 7 A143T/R118C subjects (36.8\%). Application of HAM-D indicated depression in 9 of them (47.4\%). Six subjects were classified as having mild symptoms; 1 subject was as considered as having moderate depression and 2 subjects as having severe depression. Of those, 8 subjects were not on any antidepressant therapy and information about prescription of a female subject previously diagnosed with depression was not available. HAM-D results had a positive correlation with MSSI values $(\mathrm{r}=0.63, \mathrm{p}=0.30)$, with BPI severity $(\mathrm{r}=0.58 ; \mathrm{p}<0.001)$ and BPI interference $(r=0.58 ; \mathrm{p}<0.001)$.

Prevalence of depression in A143T/R118C as indicated by HAM-D was not statistically different from classic FD patients ( $47.4 \%$ vs. $56.8 \% \mathrm{p}=0.51$ ).

\section{Sleep Disturbances}

Insomnia and/or unrefreshing sleep were reported by $9 \mathrm{~A} 143 \mathrm{~T} /$ R118C subjects (47.3\%). PSQI showed sleep disturbances in 10 subjects (52.6\%). PSQI values correlated with MSSI values $(\mathrm{r}=0.52 ; \mathrm{p}=0.22)$, with HAM-D results $(\mathrm{r}=0.54 ; \mathrm{p}=0.08)$ and BPI interference values $(r=0.30 ; \mathrm{p}<0.001)$. No correlation was found between PSQI values and BPI severity values. There were no reports of use of hypnotics or sleep inductors, Information about prescription of a female subject previously diagnosed with depression was not available.

Prevalence of sleep disturbances in A143T/R118C as indicated by PSQI was not statistically different from classic FD patients (52.6\% vs. $59.5 \% \mathrm{p}=0.63)$.

\section{Disability}

In A143T/R118C subjects, mean HAQ-DI was 0.458 for moderate and 0.127 for mild severity subjects. None of the subjects scored above 1. HAQ-DI values correlated with MSSI scores ( $\mathrm{r}=0.56$; $\mathrm{p}<0.001)$, with HAM-D values $(\mathrm{r}=0.57$; $\mathrm{p}<0.001)$, with PSQI values $(r=0.40 ; p<0.001)$, with BPI severity $(r=0.68 ; p<0.001)$ and BPI interference values $(r=0.64 ; p=0.001)$.

Overall values of HAQ-DI were not different from A143T/ R118C subjects when compared to classic FD patients $(0.162 \pm 0.209$ vs. $0.255 \pm 0.313, \mathrm{p}=0.26$ ).

\section{Quality of Life}

In A143T/R118C subjects, SF-36 scores (lower the score, greater the disability) in physical functioning $(\mathrm{r}=-0.75, \mathrm{p}<0.001)$ and physical role functioning $(\mathrm{r}=-0,43, \mathrm{p}<0.0001)$ correlated with HAQ-DI scores; bodily pain scores correlated with both BPI Severity $(r=-0.81 ; p<0.001)$ and Interference $(r=-0.65 ; p<0.001)$ scores; mental health component $(\mathrm{r}=-0.71 ; \mathrm{p}<0.001)$ correlated with HAM-D score; and general health perceptions $(r=-0.71$; $\mathrm{p}<0.001$ ) correlated with MSSI score.

SF-36 analysis showed significant differences in raw scores between A143T/R118C subjects and classic FD patients from the same region, only in physical functioning $(73.68 \pm 20.19$ vs. $56.08 \pm 24.75, \mathrm{p}=0.01)$ and general health perceptions $(70.68 \pm 17.06$ vs. $48.89 \pm 21.03, \mathrm{p}=0.0003$ ) as shown in Table 2 . 
Table 1. R118C and A143T subjects' demographic and laboratory information.

\begin{tabular}{|c|c|c|c|c|c|c|}
\hline Patient \# & Variant & Gender & Age & $\begin{array}{l}\text { Alpha-Galactosidase A } \\
\text { reference range } \\
\geq 15.3 \mu \mathrm{mol} / 1 / \mathrm{h}\end{array}$ & $\begin{array}{l}\text { Lyso-Gb3 } \\
\text { reference range } \\
\leq 1.8 \mathrm{ng} / \mathrm{ml}\end{array}$ & MSSI \\
\hline $1 *$ & A143T & $\mathrm{F}$ & 61 & na & 1.1 & 20 \\
\hline $2 *$ & $\mathrm{R} 118 \mathrm{C}$ & $M$ & 60 & 7.6 & 0.8 & 23 \\
\hline 3 & A143T & $\mathrm{F}$ & 41 & na & 1.1 & 17 \\
\hline 4 & A143T & $\mathrm{F}$ & 25 & na & 1.1 & 13 \\
\hline 5 & R118C & $\mathrm{F}$ & 18 & na & 0.9 & 14 \\
\hline 6 & $\mathrm{R} 118 \mathrm{C}$ & $\mathrm{F}$ & 35 & na & 1.0 & 6 \\
\hline 7 & $\mathrm{R} 188 \mathrm{C}$ & $\mathrm{F}$ & 35 & na & 0.9 & 3 \\
\hline 8 & R188C & $\mathrm{F}$ & 39 & na & 0.9 & 7 \\
\hline 9 & $\mathrm{R} 188 \mathrm{C}$ & $\mathrm{F}$ & 9 & na & 1.1 & 4 \\
\hline 10 & $\mathrm{R} 188 \mathrm{C}$ & $\mathrm{F}$ & 57 & na & 1.0 & 6 \\
\hline 11 & $\mathrm{R} 188 \mathrm{C}$ & $\mathrm{F}$ & 30 & na & 0.8 & 5 \\
\hline 12 & $\mathrm{R} 188 \mathrm{C}$ & $\mathrm{F}$ & 35 & na & 0.8 & 0 \\
\hline 13 & A143T & M & 38 & 4.7 & 1.6 & 5 \\
\hline 14 & $\mathrm{R} 118 \mathrm{C}$ & $M$ & 49 & 3.8 & 1.1 & 8 \\
\hline 15 & $\mathrm{R} 188 \mathrm{C}$ & $M$ & 66 & 7.7 & 1.1 & 1 \\
\hline 16 & $\mathrm{R} 188 \mathrm{C}$ & $M$ & 51 & 10.6 & 1.0 & 4 \\
\hline 17 & $\mathrm{R} 188 \mathrm{C}$ & $M$ & 29 & 8.3 & 1.3 & 7 \\
\hline 18 & $\mathrm{R} 188 \mathrm{C}$ & $M$ & 36 & 7.4 & 1.1 & 4 \\
\hline 19 & $\mathrm{R} 188 \mathrm{C}$ & $M$ & 59 & 7.1 & 1.1 & 7 \\
\hline
\end{tabular}

*Currently on enzyme replacement therapy; MSSI: Mainz Symptom Severity Index; Lyso-Gb3: lyso-globotriaosylsphingosine; na: not available.

Table 2. Comparison of SF-36 results between classic FD patients and A143T and R118C subjects from the same region (State of São Paulo, Brazil).

\begin{tabular}{|c|c|c|c|}
\hline SF-36 Concepts & $\begin{array}{c}\text { A143T/R118C subjects } \\
(\mathrm{N}=19) \\
\text { Mean } \pm \text { SD }\end{array}$ & $\begin{array}{c}\text { FD patients* } \\
\left(\begin{array}{l}(\mathrm{N}=37) \\
\text { Mean } \pm \text { SD }\end{array}\right.\end{array}$ & $p$-value \\
\hline Vitality & $55.79 \pm 22.02$ & $54.05 \pm 20.53$ & 0.78 \\
\hline Physical functioning & $73.68 \pm 20.19$ & $56.08 \pm 24.75$ & 0.01 \\
\hline Bodily pain & $64.32 \pm 26.28$ & $62.30 \pm 23.47$ & 0.78 \\
\hline General health perceptions & $70.68 \pm 17.06$ & $48.89 \pm 21.03$ & 0.0003 \\
\hline Physical role functioning & $71.05 \pm 33.70$ & $51.35 \pm 39.40$ & 0.07 \\
\hline Emotional role functioning & $61.40 \pm 44.93$ & $53.15 \pm 42.06$ & 0.51 \\
\hline Social role functioning & $78.95 \pm 20.30$ & $71.28 \pm 25.48$ & 0.27 \\
\hline Mental health & $67.79 \pm 20.00$ & $66.59 \pm 22.48$ & 0.85 \\
\hline
\end{tabular}

SD. Standard deviation. * Rosa Neto et al. 2019

\section{Discussion}

The diagnosis of Fabry disease requires thorough evaluation of signs and symptoms present in a patient but also detailed family history. $[2,12]$ Information should be combined with laboratory, imaging, and pathology reports, whenever possible, and assessed by an experienced multidisciplinary team to avoid misinterpretation of results.

Health-related quality of life is considerably reduced in patients with FD secondary to somatic and psychological impairment, and formal psychiatric and neuro-psychological evaluation should be included in the patient's evaluation. [4,40-43]
This is in consonance with a recently published paper by Loeb et al. [44] where the authors investigated the frequency of cognitive impairment in FD patients. They found one-third of Danish FD patients to have cognitive impairment in different domains, regardless of disease severity or presence of depression. Interestingly, they noted that subjective (patient complaints) and objective (test performances) evaluations were unable to identify the same proportion of affected patients thus emphasizing the need for detailed neuro-psychological testing.

The use of structured instruments during assessment of patients enhances recognition of signs and symptoms and, consequently, health care, quality of life and tailoring of therapies. [40] 
The findings of this study reinforce the benign nature of A143T and R118C variants in this small cohort in which female subjects had normal lyso-Gb3 levels and male subjects had low residual alpha-galactosidase levels but lyso-Gb3 within the reference range and no unequivocal evidence FD-related manifestations or documentation of target-tissue deposits consistent with Fabry disease.

It is understandable that some of those patients may be diagnosed with Fabry disease because of unexplained signs and symptoms, laboratory official reports classifying these variants as pathogenic, and the availability of published papers in the medical literature where A143T or R118C subjects are considered affected, especially in cases with elevation of Lyso-Gb3.[45-49]

Our results show that if you use the MSSI to evaluate severity in those subjects without establishing a definite diagnosis, scores may disclose "moderate" disease in some of the patients. Practitioners should be careful not to over-emphasize these findings without definitive evidence of substrate accumulation, either directly by tissue analysis or indirectly by biomarker analysis. This is particularly important in Brazil where it is presumed that $\mathrm{R} 118 \mathrm{C}$ could be a frequent finding because of our history of Portuguese colonization.[14,15]

Our results also underline a need of better assessment of depression, quality of sleep, quality of life, functionality, and pain in patients in general, regardless of what underlying disease they may have. This is consistent with studies in heart failure and chronic kidney disease in general.[50-51]

The presence of pain as assessed by BPI in this cohort of A143T/ R118C subjects was prevalent, alongside elevated use of over-thecounter analgesics and the lack of prescription of pain modulators. Pain scores correlated with depression, sleep disturbances and quality of life scores and could be routinely measured in order to reduce its impact on other aspects of the disease.

Depression was also under-recognized and under-treated in this cohort and sleep disturbances and disability were prevalent. Of note, the prevalence of depression, sleep disturbances and disability in A143T/R118C subjects was not different from classic FD patients. This should be regarded as a possible confounding factor when trying to establish diagnosis and determine pathogenicity of a specific variant. Our results show less severe scores for physical functioning and general health perceptions in A143T/R118C subjects in this cohort than FD patients. A previous report on HRQOL assessment in FD patients treated with agalsidase beta from the Fabry Registry also presented baseline scores for different SF-36 domains. Mean scores for physical functioning were 67.5 and 59 , and for general health perceptions, 43.6 and 43.9 , for men and women, respectively. Although not directly comparable, those numbers reinforce the notion of veritable FD patients being more severely affected in those domains.[52]

There are limitations to this work. Our report included only a small number of A143T/R118C subjects and there was no control group with subjects without the presence of such variants. Moreover, the fact that A143T/R118C subjects were identified after a screening process in a hemodialysis center configures a selection bias. Nonetheless, a broad examination was undertaken to ensure comprehensiveness of the data at the moment of assessment, but it was not possible, nor the aim of this study, to determine the etiology of signs and symptoms present in those subjects.

\section{Conclusions}

Subjects with A143T and R188C GLA gene variants in this cohort had normal levels of lyso-Gb3 and no evidence of Fabry disease. Depression, sleep disturbances and disability were under-recognized in subjects with A143T and R118C GLA gene variants in this cohort, but their prevalence was not different from what is seen in classic FD patients. General health status was poorer for FD patients than A143T/R118C subjects.

These results reinforce the need to fully assess those patients and to pursue what might be causing or interfering with these findings. Whether such manifestations are related to comorbid pathology is yet to be determined. Prescription of enzyme replacement therapy should be reexamined in the setting of lack of definitive evidence of pathogenicity.

Future studies in this topic should include larger samples and control groups, preferably from the same background, to better understand the prevalence and the significance of A143T and R118C GLA gene variants in the population.

\section{Abbreviations}

FD: Fabry Disease

GVUS: Genetic Variant of Unknown Significance

ERT: Enzyme Replacement Therapy

M: male

F: female

MSSI: Mainz Symptom Severity Index

QoL: Quality of Life

PROs: Patient-Reported Outcomes

HR-QoL: Health-related Quality of life

HAM-D: Hamilton Depression Rating Scale

PSQI: Pittsburgh Sleep Quality Index

BPI: Brief Pain Inventory

HAQ-DI: Health Assessment Questionnaire Disability Index

SF-36: Short-Form Health Survey 36

QALYs: Quality Adjusted Life Years

\section{Funding}

FAPE - Brazilian Society of Rheumatology Research Fund.

\section{Declaration of Conflicting Interests}

NSRN declares having received speaker's and advisory board fees from Shire HGT, now Takeda Pharmaceuticals. JCBB declares that spouse received speaker's and advisory board fees from Shire HGT, now Takeda Pharmaceuticals. RMRP has nothing to disclose. 


\section{Data Sharing Statement}

The datasets used and/or analyzed during the current study are available from the corresponding author on reasonable request.

\section{Supplementary Material}

The following online material is available for this article: Description of the questionnaires used in this research.

\section{References}

1. Schiffmann R. Fabry disease. Handb Clin Neurol. 2015;132:231-248. doi:10.1016/B978-0-444-62702-5.000172

2. Germain DP. Fabry disease. Orphanet J Rare Dis. 2010;5:30. doi:10.1186/1750-1172-5-30

3. Tuttolomondo A, Pecoraro R, Simonetta I, et al. Neurological complications of Anderson-Fabry disease. Curr Pharm Des. 2013;19(33):6014-6030. doi:10.2174/13 816128113199990387

4. Wanner C, Arad M, Baron R, et al. European expert consensus statement on therapeutic goals in Fabry disease. Mol Genet Metab. 2018;124(3):189-203. doi:10.1016/j. ymgme.2018.06.004

5. Arends M, Körver S, Hughes DA, Mehta A, Hollak CEM, Biegstraaten M. Phenotype, disease severity and pain are major determinants of quality of life in Fabry disease: results from a large multicenter cohort study. J Inherit Metab Dis. 2018;41(1):141-149. doi:10.1007/s10545-017-0095-6

6. Tuttolomondo A, Simonetta I, Duro G, et al. Inter-familial and intra-familial phenotypic variability in three Sicilian families with Anderson-Fabry disease. Oncotarget. 2017;8(37):61415-61424. doi:10.18632/oncotarget.18250

7. Tuttolomondo A, Pecoraro R, Simonetta I, Miceli S, Pinto A, Licata G. Anderson-Fabry disease: a multiorgan disease. Curr Pharm Des. 2013;19(33):5974-5996. doi:10.2174/13 816128113199990352

8. Spada M, Pagliardini S, Yasuda M, Tukel T, Thiagarajan G, Sakuraba H, Ponzone A, Desnick RJ. High incidence of later-onset Fabry disease revealed by newborn screening. Am J Hum Genet. 2006;79(1):31-40. doi:10.1086/504601

9. Schiffmann R, Fuller M, Clarke LA, Aerts JM. Is it Fabry disease? Genet Med. 2016;18(12):1181-1185. doi:10.1038/ gim.2016.55

10. Van der Tol L, Smid BE, Poorthuis BJ, et al. A systematic review on screening for Fabry disease: prevalence of individuals with genetic variants of unknown significance. J Med Genet. 2014;51(1):1-9. doi:10.1136/ jmedgenet-2013-101857
11. Kramer J, Weidemann F. Biomarkers for Diagnosing and Staging of Fabry Disease. Curr Med Chem. 2018;25(13):15301537. doi:10.2174/0929867324666170616102112

12. Germain DP, Fouilhoux A, Decramer S, et al. Consensus recommendations for diagnosis, management, and treatment of Fabry disease in paediatric patients. Clin Genet. 2019;96(2):107-117. doi:10.1111/cge.13546. DOI: 10.3390/ijms19123726

13. Duro G, Zizzo C, Cammarata G, et al. Mutations in the GLA Gene and LysoGb3: Is It Really Anderson-Fabry Disease? Int J Mol Sci. 2018;19(12): 3726.

14. Ferreira S, Ortiz A, Germain DP, et al. The alphagalactosidase A p. Arg118Cys variant does not cause a Fabry disease phenotype: data from individual patients and family studies. Mol Genet Metab. 2015;114(2):248-258. doi:10.1016/j.ymgme.2014.11.004

15. Baptista MV, Ferreira S, Pinho-e-Melo T, et al. Portuguese Young Stroke Investigators. Stroke. 2010;41(3):431-436. doi:10.1161/strokeaha.109.570499

16. Hauth L, Kerstens J, Yperzeele L, Eyskens F, Parizel PM, Willekens B. Galactosidase Alpha p.A143T Variant Fabry Disease May Result in a Phenotype with Multifocal Microvascular Cerebral Involvement at a Young Age. Front Neurol. 2018;9:336. doi:10.3389/fneur.2018.00336

17. Desnick RJ, Doheny D, Chen B, et al. Fabry disease: the a-galactosidase A (GLA) c.427G >A (A143T) mutation, effect of the 5'-10C $>$ T polymorphism. Mol Genet Metab. 2015;114:S11-S130. doi:10.1016/j.ymgme.2014.12.067

18. Müller MJ. Neuropsychiatric and psychosocial aspects of Fabry disease. In: Mehta A, Beck M, Sunder-Plassmann G, editors. Fabry Disease: Perspectives from 5 Years of FOS. Oxford: Oxford PharmaGenesis; 2006. Chapter 29. https:// www.ncbi.nlm.nih.gov/books/NBK11618/

19. Arends M, Hollak CE, Biegstraaten M. Quality of life in patients with Fabry disease: a systematic review of the literature. Orphanet J Rare Dis. 2015;10:77. doi:10.1186/ s13023-015-0296-8

20. Johnston BC, Miller PA, Agarwal A, et al. Limited responsiveness related to the minimal important difference of patient-reported outcomes in rare diseases. J Clin Epidemiol.2016;79:10-21. doi:10.1016/j.jclinepi.2016.06.010

21. Lelieveld IM, Böttcher A, Hennermann JB, Beck M, Fellgiebel A. Eight-year follow-up of neuropsychiatric symptoms and brain structural changes in Fabry disease. PLoS One. 2015;10(9):e0137603. doi:10.1371/journal. pone. 0137603

22. Wagner M, Krämer J, Blohm E, et al. Kidney function as an underestimated factor for reduced health related quality of life in patients with Fabry disease. BMC Nephrol. 2014;15:188. doi: 10.1186/1471-2369-15-188 
23. Talbot A, Hammerschlag G, Goldin J, Nicholls K. Sleep Disturbance, Obstructive Sleep Apnoea and Abnormal Periodic Leg Movements: Very Common Problems in Fabry Disease. JIMD Rep. 2017;31:37-44. doi: 10.1007/8904_2016_549

24. Ali N, Gillespie S, Laney D. Treatment of Depression in Adults with Fabry Disease. JIMD Rep. 2018;38:13-21. doi:10.1007/8904_2017_21

25. Gaisl T, Nowak A, Sievi NA, Gerard N, Clarenbach CF, Kohler M, et al. Obstructive sleep apnea and quality of life in Fabry disease: a prospective parallel cohort study. Sleep Breath. 2020;24(1):95-101. doi:10.1007/s11325-01901832-4

26. Smid BE, van der Tol L, Cecchi F, et al. Uncertain diagnosis of Fabry disease: consensus recommendation on diagnosis in adults with left ventricular hypertrophy and genetic variants of unknown significance. Int J Cardiol. 2014;177(2):400-408. doi:10.1016/j.ijcard.2014.09.001

27. Smid BE, van der Tol L, Biegstraaten M, Linthorst GE, Hollak CE, Poorthuis BJ. Plasma globotriaosylsphingosine in relation to phenotypes of Fabry disease. J Med Genet. 2015;52(4):262-268. doi:10.1136/jmedgenet-2014-102872

28. Smid BE, Hollak CE, Poorthuis BJ, et al. Diagnostic dilemmas in Fabry disease: a case series study on GLA mutations of unknown clinical significance. Clin Genet. 2015;88(2):161-166. doi:10.1111/cge.12449

29. Cleeland CS, Ryan KM. Pain assessment: global use of the Brief Pain Inventory. Ann Acad Med Singapore. 1994;23(2):129-138.

30. Ferreira KA, Teixeira MJ, Mendoza TR, Cleeland CS. Validation of Brief Pain Inventory to Brazilian patients with pain. Support Care Cancer. 2011;19(4):505-511. doi:10.1007/s00520-010-0844-7

31. Hamilton M. Development of a rating scale for primary depressive illness. Br J Soc Clin Psychol. 1967;6(4):278-296. doi:10.1111/j.2044-8260.1967.tb00530.x

32. Freire MA, Figueiredo VLM, Gomide A, et al. Hamilton Scale: study of the psychometric characteristics in a sample from Southern Brazil. J Bras Psiquiatr. 2014;63(4):281-189. doi:10.1590/0047-2085000000036

33. Buysse DJ, Reynolds III CF, Monk TH, Berman SR, Kupfer DJ. The Pittsburgh Sleep Quality Index: A new instrument for psychiatric practice and research. J Psych Res. 1989;28(2):193-213. doi:10.1016/0165-1781(89)90047-4

34. Bertolazi AN, Fagondes SC, Hoff LS, et al. Validation of the Brazilian Portuguese version of the Pittsburgh Sleep Quality Index. Sleep Med. 2011;12(1):70-75. doi:10.1016/j. sleep.2010.04.020
35. Fries JF, Spitz P, Kraines RG, Holman HR. Measurement of patient outcome in arthritis. Arthritis Rheum. 1980;23(2):137-145. doi:10.1002/art.1780230202

36. Ferraz MB, Oliveira LM, Araujo PM, Atra E, Tugwell P. Cross-cultural reliability of the physical ability dimension of the health assessment questionnaire. J Rheumatol. 1990;17(6):813-817.

37. Ware JE Jr, Sherbourne CD. The MOS 36-item short-form health survey (SF-36). I. Conceptual framework and item selection. Med Care. 1992;30(6):473-483.

38. Ciconelli RM, Ferraz MB, Santos W, Meinão I, Quaresma MR. Tradução para a língua portuguesa e validação do questionário genérico de avaliação de qualidade de vida SF36 (Brasil SF-36). Rev Bras Reumatol. 1999;39(3):143-145.

39. Whybra C, Kampmann C, Krummenauer F, et al. The Mainz Severity Score Index: a new instrument for quantifying the Anderson-Fabry disease phenotype, and the response of patients to enzyme replacement therapy. Clin Genet. 2004;65(4):299-307. doi:10.1111/j.1399-0004.2004.00219.x

40. Rosa NS Neto, Bento JCB, Pereira RMR. Depression, sleep disturbances, pain, disability, and quality of LIFE in Brazilian Fabry disease patients. Mol Genet Metab Rep. 2019;22:100547. doi:10.1016/j.ymgmr.2019.100547

41. Cole AL, Lee PJ, Hughes DA, Deegan PB, Waldek S, Lachmann RH. Depression in adults with Fabry disease: a common and under-diagnosed problem. J Inherit Metab Dis. 2007;30(6):943-951. doi:10.1007/s10545-007-0708-6

42. Oliveira FL, Alegra T, Dornelles A, et al. Quality of life of Brazilian patients with Gaucher disease and Fabry disease. JIMD Rep. 2013;7:31-37. doi:10.1007/8904_2012_136

43. Löhle $\mathrm{M}$, Hughes D, Milligan A, et al. Clinical prodromes of neurodegeneration in Anderson-Fabry disease. Neurology. 2015;84(14):1454-1464. doi:10.1212/ WNL.0000000000001450

44. Loeb J, Feldt-Rasmussen U, Madsen CV, Vogel A. Cognitive Impairments and Subjective Cognitive Complaints in Fabry Disease: A Nationwide Study and Review of the Literature. JIMD Rep. 2018;41:73-80. doi:10.1007/8904_2018_103

45. Eng CM, Ashley GA, Burgert TS, Enriquez AL, D'Souza M, Desnick RJ. Fabry disease: thirty-five mutations in the alpha-galactosidase A gene in patients with classic and variant phenotypes. Mol Med. 1997;3(3):174-182.

46. Corry A, Feighery C, Alderdice D, Stewart F, Walsh M, Dolan OM. A family with Fabry disease diagnosed by a single angiokeratoma. Dermatol Online J. 2011;17(4):5.

47. Turaça LT, Pessoa JG, Motta FL, et al. New mutations in the GLA gene in Brazilian families with Fabry disease. $J$ Hum Genet. 2012;57(6):347-351. doi:10.1038/jhg.2012.32 
48. Caetano F, Botelho A, Mota P, Silva J, Leitão Marques A. Fabry disease presenting as apical left ventricular hypertrophy in a patient carrying the missense mutation R118C. Rev Port Cardiol. 2014;33(3):183.e1-5. doi:10.1016/j. repc.2013.11.005

49. Talbot A, Nicholls K. Elevated Lyso-Gb3 Suggests the R118C GLA Mutation Is a Pathological Fabry Variant. JIMD Rep. 2019;45:95-98. doi:10.1007/8904_2018_146

50. Simões E, Silva AC, Miranda AS, Rocha NP, Teixeira AL. Neuropsychiatric Disorders in Chronic Kidney Disease. Front Pharmacol. 2019;10:932. doi:10.3389/ fphar.2019.00932
51. Sheffler JL, Schmiege SJ, Sussman J, Bekelman DB. A longitudinal analysis of the relationships between depression, fatigue, and pain in patients with heart failure. Aging Ment Health. 2020; [ahead of print] doi:10.1080/13 607863.2020.1855626.

52. Watt T, Burlina AP, Cazzorla C, et al. Agalsidase beta treatment is associated with improved quality of life in patients with Fabry disease: findings from the Fabry Registry. Genet Med. 2010;12(11):703-712. doi:10.1097/ GIM.0b013e3181f13a4a 